REVISTA DE DERECHO UNED, NÚM. 18, 2016

PRIMER ACCÉSIT

\title{
LA PROYECCIÓN DE LA IMPARCIALIDAD EN EL SISTEMA JUDICIAL DEL SIGLO XXI
}

\author{
PROJECTION OF FAIRNESS IN THE JUDICIAL \\ SYSTEM OF THE XXI CENTURY
}

Silvia Conde García

Resumen: El presente estudio analiza la imparcialidad como principio que debe acompañar a la función judicial unido a la disquisición acerca de la conveniencia de ampliar el criterio de interpretación del juzgador en su labor diaria de impartir justicia. Asimismo, se incide en la presencia de esta garantía dentro del proceso y los modelos que se han defendido a lo largo de la historia para buscar su proyección en el sistema judicial del siglo XXI y ello porque la referencia a la imparcialidad, como cualidad del juzgador, puede ser definida y garantizada por reglas o naturalizado como principio, su materialización requiere analizar cuáles han sido las condiciones y atribuciones otorgadas al juzgador por el ordenamiento jurídico en cada momento histórico con el objetivo de poder concretar la concurrencia de esta garantía procesal y con ella poder cumplir la labor judicial que el pueblo ha confiado a los jueces.

Abstract: This study analyzes the fairness principle that must accompany the judicial function attached to the disquisition about the desirability of expanding the criteria of interpretation of the judge in their daily work of administering justice. Regional influences the presence of this warranty within the process and the models have defended throughout history to find its projection in the judicial system of the XXI century and this is because the reference to fairness, as quali- 
ty of trier, can be defined and guaranteed by rules or naturalized as a principle, its realization requires analyzing what were the conditions and privileges granted by law the judge in each historical period with the aim to realize the concurrence of this procedural guarantee would to fulfill the judicial work that the people entrusted to judges.

Palabras clave: principio de imparcialidad, derecho a un juez imparcial, sistema de principios, Zagrebelsky.

Keywords: principle of impartiality, the right to an impartial judge, system of principles, Zagrebelsky.

Recepción original: 24/11/2015

Aceptación original: 15/03/2016

Sumario: I. Introducción. II. La imparcialidad como garantía procesal. III. Proyección de la imparcialidad en los sistemas judiciales: $1 .^{\circ}$ El juez dentro del formalismo legalista. $2{ }^{\circ}$ El juez dentro de una pirámide normativa. $3 .^{\circ}$ El juez dentro de un sistema de reglas en Hart. 4. ${ }^{\circ}$ El juez dentro de una discrecionalidad judicial. 5. ${ }^{\circ}$ El juez dentro de un sistema de principios. $6 .^{\circ}$ El juez dentro de un derecho dúctil. IV. Conclusiones. V. Bibliografía.

\section{INTRODUCCIÓN}

«El que tiene por Juez a un acusador, necesita a Dios como abogado.» (G. Radbruch)

En un Estado Social y democrático de Derecho como el que consagra la Constitución Española de 1978, la percepción por los ciudadanos de que la Administración de Justicia funciona con imparcialidad constituye un elemento esencial para lograr la confianza de los justiciables en que la justicia verdaderamente emana del pueblo y se administra en nombre del Rey por jueces independientes, inamovibles, responsables y sometidos únicamente al imperio de la ley.

Pese a que esta norma suprema no hace referencia a la imparcialidad del juzgador, resulta necesario tomar conciencia de la relevancia de este principio dentro de una sociedad que clama como valores esenciales para la convivencia, la igualdad y la justicia, este valor es un objetivo a conseguir y ello puede convertir a la imparcialidad en piedra filosofal y al juez en alquimista jurídico porque es el llamado a transformar cada realidad en objeto de derecho para dar a cada uno 
lo suyo ${ }^{1}$, así se puede pensar que un derecho que no sirve para hacer justicia no es verdadero derecho y un juez que no imparte justicia no es verdadero juez, pero para esta tarea se requiere que el juzgador no tenga prejuicio, ni con las partes, ni con el objeto del litigio, esto es, se le debe exigir que sea imparcial, de tal manera que la imparcialidad debe ser una de las características definitorias de la función jurisdiccional, y ello, pese a que la Constitución Española no se haya detenido en esta garantía del procedimiento aun cuando es una regla esencial en el desarrollo del mismo, sin cuya presencia, el concepto de un juicio justo quedará vacío de contenido.

En el modelo clásico de Estado de Derecho ideado por Montesquieu, el poder judicial no era más que la «boca de la ley», el poder legislativo era el auténtico protagonista, en el legislador se concentraba todo el poder porque era de quién derivaba la legitimidad del sistema, su crisis comienza cuando el pueblo soberano toma conciencia y se enfrenta a un legislador que no atiende a los valores proclamados en las Declaraciones de derechos y su resultado será la formación de los Estados constitucionales en los que el juez va a ver incrementado paulatinamente su poder ya que, en su labor de interpretación judicial para conseguir una decisión justa y motivada, deberá acudir a un juicio de razonabilidad.

En efecto, la propia necesidad del juez de administrar justicia va a producir un desplazamiento de la concepción del derecho bajo un sistema basado fundamentalmente en reglas hacia un sistema basado en principios constitucionales, criterio que late en la actual Europa continental ${ }^{2}$ y siendo un método propio de los países del Common law, aquellos que tienden a concebir un derecho abierto al poder discrecional del juzgador sustentado en que la interpretación de las normas se realiza mediante la argumentación jurídica.

Con ello, los Estados constitucionales de Derecho están otorgando un papel protagonista al juez a la par que el legislador pierde poder, en tales sistemas las normas promulgadas por el Parlamento, quedan sometidas a un proceso de validez constitucional por parte de los jueces -piénsese en la cuestión de constitucionalidad-, de tal manera

${ }^{1}$ Así comienzan las Instituciones de Justiniano «Iustitia est constans et perpetua voluntas ius suum cuique tribuendi». Libro Primero de las reglas de Ulpiano (D. 1.1. $10 \mathrm{pr})$.

${ }^{2}$ Un ejemplo de ello se puede percibir en el asunto prejudicial C-154/15 que se sigue ante el Tribunal de Justicia de la Unión Europea en relación al alcance de la nulidad que los Tribunales Nacionales deben dar a la cláusula financiera relativa al interés variable fijado como mínimo (cláusula suelo) aplicable durante toda la vida en algunos préstamos hipotecarios. 
que, dentro de estos sistemas democráticos, las normas ya no son algo acabado que el juez de forma autómata aplica, a modo de matemático jurídico, sino que el juzgador motiva sus decisiones mediante una cognición judicial, llámese razonabilidad, ponderación, proporcionalidad, etc., convirtiéndose con ello en un hermenéutico jurídico. Este aumento del protagonismo judicial en aplicar el Derecho en bastantes ocasiones se está realizando sin que el propio juzgador sea realmente consciente de su hermenéutica ${ }^{3}$ para tomar la decisión a través de la cual se está cristalizando el valor de la justicia ${ }^{4}$, quizás porque lo realice bajo un pensamiento de que la ley debe ser aplicada a cada caso en concreto sin grandes construcciones o dificultades pero es que los jueces ya no son la boca de la ley sino que sus funciones se han multiplicado no solo por la carga de trabajo que a diario soportan los juzgados españoles, sino de forma cualitativa ${ }^{5}$, unas de las funciones más importantes es la de control y freno al ejercicio de poder por parte de los otros poderes del Estado, así puede hacerlo mediante el control difuso de constitucionalidad de las normas, estatales y autonómicas, o siendo garante del respeto a los derechos fundamentales de los ciudadanos, labor protectora de los valores esenciales para la comunidad, garantía, que, al igual, resulta desconocida para la mayor parte de la ciudadanía.

Esta relevancia del juzgador en los Estados constitucionales de Derecho también puede ser objeto de serias críticas ya que un juez

${ }^{3}$ Destaca ANDRÉS IBÁÑEZ que «Hoy no es en absoluto excepcional que el juez opere con principios sin conciencia clara de la amplitud real de los márgenes recorridos en la construcción de la resolución, como quien tuviera el convencimiento ingenuo de estar haciéndolo con reglas. Porque -correctamente- persuadido del valor normativo vinculante de aquéllos, carece, sin embargo, de los recursos técnico-culturales adecuados para evaluar en todo su alcance los factores de innovación que introducen en la práctica jurisdiccional», P. ANDRÉS IBÁÑEZ «No conviene «matar»al «notario». A propósito de jurisdicción y de Derecho dúctil (en España)». Anuario de Filosofía del Derecho XIII (1996), p. 49.

${ }^{4}$ El concepto de justicia es una de las descripciones más discutidas para la filosofía del Derecho, la doctrina mayoritaria considera que no existe una fórmula válida, inmutable y universal para todo tiempo y lugar sobre el ideal de justicia, en este relativismo axiológico se posiciona Hans Kelsen en su obra ¿Qué es la Justicia?, Kelsen señala que no sabe, ni puede saber qué es la justicia y apunta que «la justicia se encuentra en aquel ordenamiento social bajo cuya protección puede prosperar la búsqueda de la verdad. Mi justicia es la justicia de la libertad, la justicia de la democracia: en una palabra, la justicia de la tolerancia». KELSEN, H. ¿Qué es justicia? Barcelona, Planeta De Agostini, 1993, pp. 35-64.

${ }^{5}$ GÓMEZ MARTÍNEZ indica que el juez del siglo XXI es un juez Hermes ante un escenario de caos judicial en las que el juez se ha visto envuelto por el aumento y diversidad de sus funciones, GÓMEZ MARTÍNEZ, C.: «El juez ante el caos judicial, Hermes o el Dios de las pequeñas cosas». Ética judicial: Reflexiones desde jueces para la democracia. Fundación Antonio Carretero, Madrid, pp. 105-106. 
que utiliza e interpreta principios constitucionales para dotar de contenido sus resoluciones judiciales podría quebrantar los principios de seguridad jurídica y de igualdad de los ciudadanos en la aplicación de la ley, por ello, habrá quienes defiendan el retorno de la decisión judicial a la ley como fin, y no como herramienta, con el objetivo de neutralizar cualquier tipo de arbitrariedad.

El debate está servido, la apreciación por la ciudadanía de la imparcialidad como principio que debe acompañar a la función judicial unida a la disquisición acerca de la conveniencia de ampliar el criterio de interpretación del juzgador en su labor diaria de impartir justicia lleva a preguntarse ¿En qué consiste la imparcialidad judicial y su conexión con la función de aplicación de la ley que se ha encomendado al juez dentro de las sociedades democráticas?, interrogante que requiere indagar sobre el concepto de la imparcialidad y los modelos que se han defendido en la historia de los sistemas judiciales para buscar la proyección de este principio en el siglo XXI.

\section{LA IMPARCIALIDAD COMO GARANTÍA PROCESAL}

«Siendo juez, no hagas injusticia, ni por favorecer al pobre, ni por miramientos hacia el grande: con justicia juzgarás a tu prójimo ${ }^{6}$, este versículo que recoge el Antiguo Testamento pone de manifiesto como en los primeros juicios de la historia el deber de ser imparcial se presenta como antecedente para impartir justicia puesto que la ausencia de imparcialidad determina la falta de justicia.

Con fundamentos más terrenales, piénsese en los Estados que nacen tras la II Guerra Mundial, la imparcialidad se presenta como principio inspirador de la jurisdicción ${ }^{7}$ y es elevada a regla suprema del proceso en la búsqueda de que el juez no sea parte dentro del mismo, en esta línea, Goldschimdt diferencia los conceptos de partialidad y parcialidad, «Partial significa ser parte, parcial da a entender que se juzga con prejuicios. [...] La imparcialidad consiste en poner entre paréntesis todas las consideraciones subjetivas del juzgador. Este debe sumergirse en el objeto, ser objetivo, olvidarse de su propia personalidad» ${ }^{8}$.

${ }^{6}$ Levítico 19-15.

${ }^{7}$ P. ANDRÉS IBÁÑEZ, «Imparcialidad judicial e independencia judicial», Ética Judicial: Reflexiones desde jueces para la democracia, Fundación Antonio Carretero, p. 15.

${ }^{8}$ W. GOLDSCHMIDT, «La Imparcialidad como Principio Básico del Proceso», Conducta y Norma, Librería Jurídica Valerio Abeledo, Buenos Aires, 1955, p. 133. 
Por su parte, Aguiló distingue el principio de independencia del principio de imparcialidad, el primero controla la ausencia de móviles del juez frente a influencias extrañas al derecho provenientes de la sociedad en general (frente a otros jueces, frente a los poderes del Estado, frente a la prensa, etc), mientras que la imparcialidad vela por la falta de influencias en el juzgador provenientes desde dentro del propio proceso jurisdiccional ${ }^{9}$.

Así, la imparcialidad busca eventuales móviles que pueden tachar al juzgador dentro del proceso con las partes en conflicto y/o con el propio objeto de enjuiciamiento, resultando pues, relevante la diferencia entre el principio de independencia y el principio de imparcialidad, más cuando la presencia del primero es condición necesaria para el segundo, ya que un juez independiente puede comportarse de forma parcial en la labor judicial que le ha sido encomendada y, por contra, un juez que en principio no es independiente, difícilmente podrá actuar de manera imparcial. Por ello, la esencia de la imparcialidad reside en que se presenta como un principio para el Derecho y en él se contiene los entes de razón que expresan el juicio que el propio ordenamiento jurídico persigue y en la medida que esto se legaliza, se va proyectando en reglas.

El derecho a un juez imparcial se encuentra proclamado en la denominada primera generación de derechos, dentro de los derechos civiles o individuales ${ }^{10}$ y se consolida gracias a los Estados constitucionales de Derecho ${ }^{11}$ que surgen después de la II Guerra Mundial, más tarde es elevado a derecho fundamental al presentar los caracteres de universalidad, inalienabilidad e indisponibilidad ${ }^{12}$ y, se especifica en ser una garantía para todo justiciable, así se proclama a nivel europeo en el artículo 6 del Convenio Europeo para la Protección de los Derechos Humanos y de las Libertades Fundamentales de 4 de Noviembre de 1950 «Toda persona tiene derecho a que su causa sea oída equitativa, públicamente y dentro de un plazo ra-

9 J. AGUILÓ REGLA, «Independencia e imparcialidad de los jueces», Biblioteca Jurídica virtual del Instituto de Investigaciones jurídicas de la UNAM, p. 97.

${ }^{10}$ Castro Cid, B. / Martínez Morán, N. (coord.) 18 Lecciones de Filosofía del Derecho, Manual para alumnos de la UNED, Madrid, 2008, p. 129.

${ }^{11}$ Para L. FERRAJOLI el paradigma del Estado constitucional de Derecho "no es otra cosa que esta doble sujeción del derecho al derecho, que afecta a ambas dimensiones de todo fenómeno normativo: la vigencia y la validez, la forma y la sustancia, los signos y los significados, la legitimación formal y la legitimación sustancial o, si se quiere, la «racionalidad formal» y la «racionalidad material» weberianas», L. FERRAJOLI, Derechos y garantías. La ley del más débil, traducción por Perfecto Andrés

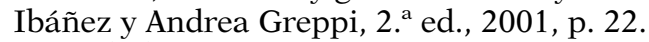

${ }^{12}$ Ibíd. 23 
zonable, por un Tribunal independiente e imparcial, establecido por ley, que decidirá los litigios sobre sus derechos y obligaciones de carácter civil o sobre el fundamento de cualquier acusación en materia penal dirigida contra ella ${ }^{13}$.

El principio de imparcialidad es un derecho de configuración legal que el propio Tribunal Europeo de Derechos Humanos se ha encargado de dotarlo de contenido, en la Sentencia de 1 de octubre de 1982 (Asunto Piersack versus Bélgica) indica que «la imparcialidad se define ordinariamente por la ausencia de prejuicios o parcialidades», definición que fue consolidando hasta llegar a la Sentencia de 24 de mayo de 1989 (Asunto Hauschildt) en la que afirma «las apariencias pueden ser importantes, está en juego la confianza que los Tribunales de una sociedad democrática deben merecer a los que acuden a ellos», surge así la doctrina que se ha venido a llamar «Teoría de la apariencia» mediante la cual se pretende diferenciar la imparcialidad subjetiva y la imparcialidad objetiva, la primera se erige en determinar la convicción personal del juez en su fuero interno a fin de excluir cualquier prejuicio previo o posterior en su toma de decisión, por contra, la imparcialidad objetiva busca ofrecer garantías suficientes para excluir cualquier clase de sospecha aunque el juez no haya exteriorizado ningún tipo de convicción personal, en el aspecto objetivo se presume la imparcialidad judicial y las sospechas deben ser probadas, por el contrario, en el ámbito subjetivo no se parte de esta presunción ${ }^{14}$.

En base a lo anterior, el derecho fundamental a tener un juez imparcial, como garantía procesal, implica que el juzgador no debe guardar conexión con el justiciable ${ }^{15}$, ni debe tener prejuicio o contacto previo con el objeto de litigio, por aquello de que las apariencias son importantes ${ }^{16} \mathrm{y}$, resultando que la posible vinculación del juzga-

${ }^{13}$ Con parecida redacción en el artículo 47 de la Carta de los Derechos Fundamentales de la Unión Europea.

${ }^{14}$ La mayor parte de resoluciones del TEDH y del Tribunal Constitucional español se reducen al ámbito objetivo del principio de imparcialidad judicial.

${ }^{15}$ En la Decisión del TEDH de 12 de junio de 2012, caso Melero Echauri c. España, la Sala inadmite una demanda de amparo europeo al entender que la demandante no reunía la condición de víctima directa de la eventual infracción del derecho a un juez imparcial y recuerda que ya el TEDH había sentado que sólo aquellas personas «cuyos derechos y obligaciones civiles están en juego pueden considerarse víctimas a efectos de los artículos 6.1 y 34 del CEDH (véase Malejčík contra Eslovaquia, núm. 6218700, apds. 36-38, 31 de enero de 2006)».

${ }^{16}$ PLUTARCO, en su obra Vidas Paralelas, narra cómo Publio Clodio Pulcro, patricio romano se enamoró de Pompeya, a su vez mujer de Julio César, y aprovechando la fiesta romana de la Buena Diosa -celebración a la que sólo podían asistir mujeres-, se coló disfrazado en la casa de César, siendo que, a su inicio, fue descubierto y por ello juzgado al ser acusado de engaño y sacrilegio; a consecuencia de este suceso, 
dor con un asunto, bien con los litigantes o/y bien con el objeto de proceso, puede poner en entredicho el debido cumplimiento de la función judicial.

En este sentido, hoy se pone el acento en la subjetividad propia del juez en el conocimiento de un procedimiento específico como factor de incertidumbre que puede afectar a la función jurisdiccional ${ }^{17}$, apunta Ferrajoli que «este investigador particular legalmente cualificado que es el juez (...) por más que se esfuerce en ser objetivo, siempre está condicionado por las circunstancias ambientales en las que actúa, por sus sentimientos, sus inclinaciones, sus emociones, sus valores ético-políticos ${ }^{18}$. Para evitar y neutralizar cualquier sospecha, la exigencia de la imparcialidad judicial debe ser máxima y debe proyectarse tanto en la actividad procesal como en la actividad extraprocesal del juez, persona que con carácter previo le ha tocado conocer de un determinado asunto, por ello deben definirse reglas que eviten cualquier legítima duda que pudiera existir en relación a la falta de idoneidad de este magistrado para el conocimiento del procedimiento.

Como se ha dicho, la ausencia de reconocimiento constitucional del principio de imparcialidad ${ }^{19}$ ha motivado que el Tribunal Constitucional haya tenido que buscar su base normativa, en un primer mo-

Julio César reprobó a Pompeya, pese a estar seguro de que su mujer no le había sido infiel, pero a él no le agradaba el hecho de que su esposa fuera sospechosa de haberle sido infiel ya que entendía que no bastaba con que la mujer del César fuera honesta, también debía parecerlo.

${ }^{17}$ Si bien no toda subjetividad del juzgador puede hacer dudar de su imparcialidad, a modo de ejemplo, se comparte la fundamentación de la Sentencia de la Sala de lo Civil del Tribunal Supremo de 13 de noviembre de 2015 que concluye que no se puede recusar a un juez porque haya sido compañero de clase del representante legal de la parte demandada bajo el argumento de que «Los jueces, como profesionales del Derecho, han estudiado en la facultad de Derecho y por tanto han sido compañeros de clase no solo de empleados bancarios que sean licenciados o graduados en Derecho, como en este caso, sino de numerosos abogados y procuradores que intervienen en los juicios. Si tuvieran que abstenerse o pudieran ser recusados cada vez que coinciden en un juicio con compañeros de clase, o con cualquiera de las personas con las que entran en contacto en su vida diaria, como ciudadanos corrientes, les resultaría imposible administrar justicia. Tampoco es admisible que el cumplimiento de elementales normas de cortesía, como lo es saludar a una persona a la que se conoce, pueda ser interpretado como un signo de parcialidad... » [FJ $\left.9^{\circ}\right]$.

${ }^{18}$ FERRAJOLI, L., Derecho y razón, 3. ${ }^{\text {a }}$ ed., Madrid, Trotta, 1998, p. 56.

${ }^{19}$ Pese a que la Constitución española no ha positivizado este principio, tal omisión no ha impedido que en el ordenamiento jurídico español se hayan definido reglas que contextualizan la exigencia del principio de imparcialidad judicial, tanto en un ámbito objetivo, como en uno subjetivo así el art. 219 de la Ley Orgánica del Poder Judicial regula una serie de causas de abstención y recusación que, de concurrir, obligan al juez a abstenerse o si el magistrado no lo hace de forma voluntaria, que los justiciables puedan conseguir que sea apartado del litigio. 
mento, como un interés directo protegido dentro del derecho fundamental al Juez ordinario predeterminado por la ley ${ }^{20}$, posteriormente, situándolo como garantía dentro del proceso $^{21}$ y sentenciando «Sin juez imparcial no hay propiamente proceso jurisdiccional» ${ }^{22}$.

Tomando como argumento esta evolución, la misma muestra como la imparcialidad es un principio que se ha desarrollado en un camino reglado, como garantía previa y esencial para todo proceso, garantizado como derecho fundamental del justiciable, donde su presencia condiciona la existencia de la propia función jurisdiccional y en el que se deposita la confianza de los ciudadanos en la administración de justicia ${ }^{23}$, resultando que si para el justiciable es un derecho, a su vez, es un deber para el juez pues deber ser imparcial; de tal manera que, la imparcialidad judicial no puede ser considerada como una garantía descriptiva del procedimiento sino prescriptiva, el equivalente a «una serie de cánones deontológicos formados por el compromiso del juez de no dejarse condicionar por finalidades externas a la investigación de lo verdadero, la honestidad intelectual que como en cualquier actividad de investigación debe cerrar el interés previo en la obtención de una determinada verdad, la actitud imparcial respecto de los intereses de las partes en conflicto y de las distintas reconstrucciones e interpretaciones de los hechos por ellas avanzadas, la independencia de juicio y la ausencia de preconceptos en el examen y en la valoración crítica de las pruebas, además de en los argumentos pertinentes para la calificación jurídica de los hechos por él considerados probados» ${ }^{24}$.

Dando un paso más en el presente estudio y dado que en los sistemas judiciales la referencia a la imparcialidad, como cualidad del juzgador, puede ser definida y garantizada por reglas o naturalizado como principio, su materialización requiere analizar cuáles han sido las condiciones y atribuciones otorgadas al juzgador por el ordenamiento jurídico en cada momento histórico.

${ }^{20}$ STC 101/1984, de 8 de noviembre [FJ $4^{\circ}$ ].

${ }^{21}$ STC 145/1988, de 12 de julio [FJ 5. ${ }^{\circ}$.

${ }^{22}$ STC 151/2000, de 12 de junio [FJ 3. ${ }^{\circ}$.

${ }^{23}$ L. FERRAJOLI apela a la confianza y miedo que pueden tener los ciudadanos «lo que deslegitima a la jurisdicción no es tanto el disenso y la crítica, que no solamente son legítimos sino que operan como factor de responsabilización, sino la desconfianza en los jueces y, peor todavía, el miedo generalizado sobre todo por la falta de garantías o las violaciones legales justamente por parte de quien está llamado a aplicar la ley y quien de la sujeción a la misma recaba su legitimidad», "Las Fuentes de legitimación de la jurisdicción», Biblioteca Jurídica virtual del Instituto de Investigaciones jurídicas de la UNAM, p. 14-15.

${ }^{24}$ L. FERRAJOLI, Derecho y razón..., op. cit., p. 60. 


\section{PROYECCIÓN DE LA IMPARCIALIDAD EN LOS SISTEMAS JUDICIALES}

En Grecia, la justicia fue recreada en la Diosa Dike, hija de Zeus, a ella se refiere el poeta Hesiodo en el siglo VII a. C., este valor se equiparó a la igualdad, que a su vez fue llevada por los pitagóricos al ámbito de la aritmética y representada en los números cuatro y nueve ${ }^{25}$, con estos antecedentes, no resulta extraño que los filósofos hayan acudido al símil de los Dioses para encomendarles la función de juzgar, así para mostrar la consistencia de sus afirmaciones, Dworkin crea dos jueces ficticios: Herbert y Hércules ${ }^{26}$ y posteriormente engendrará a Minerva ${ }^{27}$, por otro lado, Ost representa tres modelos de juez: Júpiter, Hércules y Hermes ${ }^{28}$.

La práctica jurídica del juez que discierne lo que le es debido e imparte justicia bajo un principio de imparcialidad demuestra la correspondencia entre la especificación del derecho a un juicio justo y la individuación al caso concreto como un acto de justicia ${ }^{29}$ que, a su

${ }^{25} \mathrm{Al}$ ser considerados números cuadrados, «producto del igual por el igual».

${ }^{26}$ Ambos jueces resuelven los litigios para confrontar las teorías hartiana y dworkiniana, siendo Hércules el elegido para resolver los propios argumentos de Dworkin frente a las decisiones del juez Herbert (llamándolo así en alusión a Herbert Hart).

${ }^{27} \mathrm{R}$. Dworkin también recrea a la diosa Minerva para hacer frente a las críticas que recibe su Juez Hércules, usando a esta Diosa para explicar su enfoque teórico de fuera hacia dentro, La justicia con toga, traducción por Marisa Iglesias e Íñigo Ortiz de Urbina, Marcial Pons, Madrid, 2007, pp. 64-71.

${ }^{28}$ F. OST, «Júpiter, Hércules y Hermes. Tres modelos de jueces», Revista sobre enseñanza del Derecho año 4, número 8, 2007 pp. 101-130. Este filósofo belga evoca la figura de tres Dioses para enfrentar tres imágenes del derecho en su búsqueda de un patrón para la justicia. El Juez Júpiter representa las exigencias de un Estado liberal o Estado de Derecho del siglo XIX, que ejerce su labor dentro de un sistema de monismo jurídico con una única fuente jurídica, la ley, encuentra su reflejo en el Código (Montesquieu) o en una pirámide normativa (Kelsen) y, donde el contenido de la decisión judicial se deduce de la aplicación de reglas generales que derivan de principios. Posteriormente, el autor considera que, el modelo entra en crisis, tras el nacimiento de un Estado social o asistencial del siglo XX, el cual otorga al juez innumerables tareas, surge por ello el juez Hércules, quién ya no aplicara el Código sino un dossier y no cuenta con una pirámide, sino con un embudo (figura geométrica que representa la inversión del modelo) y, en donde la ley pierde protagonismo para otorgárselo a la propia decisión del juzgador, halla como ejemplo el «legal realismo» norteamericano (Dworkin). En su estudio, Ost constata el fracaso de estos dos modelos por quedar lejos de la realidad jurídica, al reparar que la sociedad y el Derecho posmoderno merecen algo mejor, evocando así a Hermes como juez del presente y del futuro, el juez del siglo XXI, quién está llamado a interpretar el derecho recreado en una estructura de red y de «banco de datos» donde el intérprete son los «sujetos de derecho», finalmente añade algunas líneas para la configuración de una teoría que podrían servir de base al derecho en red o al derecho de Hermes.

${ }^{29}$ C. ORREGO SÁNCHEZ «Un juicio justo: la especificación del juicio legal en la filosofía jurídica analítica, la hermenéutica iusfilosófica y la teoría de la ley natural» Anuario Filosófico 44/3, 2011, p. 544. 
vez, conecta con el análisis de si el sometimiento del juez a un principio de justicia significa liberar al propio juzgador de la sujeción a las leyes, resultando preciso detenerse en las diferentes concepciones que han tratado de dar respuesta a tal cuestión.

\section{1. $\quad$ El juez dentro del formalismo legalista}

La Revolución francesa impuso una sociedad «monista» ${ }^{30}$, que presidida por los valores de la burguesía liberal, dio todo el poder a la Asamblea Nacional, en este sistema podría pensarse que el Parlamento que crea la norma debía encargarse de su cumplimiento, pero aquí se inserta el pensamiento de Montesquieu donde el ideal de libertad requiere la separación de poderes.

Por ello, al poder judicial se le encarga la aplicación de la ley (Código) y se caracteriza al ordenamiento como completo, el cual da solución a todo asunto en concreto, en este sistema judicial la labor del juzgador se limita a buscar la norma y sobre la misma emitir su fallo, se consagra la máxima de Montesquieu, los jueces eran la boca de la ley, los cuales pronuncian las palabras de la ley, como seres inanimados que no pueden moderar ni la fuerza, ni el rigor de las normas ${ }^{31}$.

El razonamiento jurídico que se sigue en este modelo es únicamente subsuntivo, marcado por el conocimiento de las leyes, y siendo una labor judicial mecánica y matemática, el juez no toma la decisión al caso, sino que se limita a aplicar la norma sin ninguna valoración, de esta forma, al no existir interpretación jurídica, el sistema no necesita la garantía previa de imparcialidad judicial porque el juez no será responsable del fallo que adopta y la sentencia va a ser la misma con independencia de que el magistrado sea o no parcial, la construcción de la resolución lo hará siguiendo un procedimiento lógico de silogismo a través de una interpretación exegética de la ley y, en el cual, si el juzgador se confunde con el resultado solo se le puede exigir que aplique correctamente la ley (Escuela de la Exégesis).

De tal manera, que el principio de imparcialidad judicial nace cuando se toma conciencia de que no hay un ordenamiento jurídico completo y pleno, por cuanto inexorablemente existen lagunas dentro del mismo, además el juzgador precisa de técnicas de interpretación

${ }^{30}$ VV. AA.: Filosofía del derecho: lecciones de hermenéutica jurídica, Madrid, Universidad Nacional de Educación a Distancia, Madrid, 2006. p. 56

${ }^{31}$ P. FERNÁNDEZ-VIAGAS BARTOLOMÉ, El juez imparcial, Comares, Granada, 1997, p.39. 
judicial porque es un hombre libre y responsable que debe argumentar las decisiones que adopta para que el justiciable pueda comprender la tangibilidad del valor de la justicia y más aún cuando la ley se perpetua en el tiempo porque si pudiera pensarse que la norma es eterna, los problemas que surgen en la vida jurídico real no lo son.

Como contrapunto al positivismo, se encuentra el modelo realista, desarrollado en el mundo anglosajón y representado por la Escuela del Derecho Libre bajo un sistema de decisionismo judicial, donde el juez decide de acuerdo con su conciencia en el caso concreto, sistema judicial en la que tampoco se garantiza la imparcialidad judicial porque el sentido de la decisión del juzgador siempre va a estar condicionada por lo motivos extrajurídicos que tenga el propio magistrado.

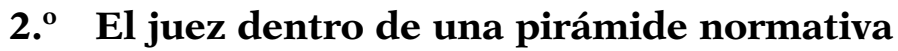

El postlegalismo conectó con el formalismo legalista como fin capaz de encontrar soluciones jurídicas en el imperio de la ley, dado que toda resolución judicial se encuentra en las reglas que el derecho previamente ha regulado para dar respuesta a los problemas sociales que se le van planteando al juzgador, aunque el positivismo ya asuma que el ordenamiento es abierto porque puede que no de una única solución al caso y complejo porque el juez debe argumentar sus decisiones conforme a una norma superior.

Con la Teoría Pura del Derecho, Hans Kelsen construye la conocida doctrina de la pirámide normativa en la que los jueces se van a encontrar facultados por una ley (norma general) para dictar una sentencia (norma individual) ${ }^{32}$, la labor judicial se realizará mediante la interpretación de la norma fundamental y conforme a las normas generales e individuales establecidas de acuerdo a ella; en este modelo, la tarea del juzgador se concreta en aplicar la norma e interpretarla de conformidad con el sistema normativo ${ }^{33}$, el cual dotará de legitimidad la decisión judicial, por ello, al juez no se le puede pedir que sea justo en su fallo a lo sumo se le podrá exigir que actué legalmente en la búsqueda de una norma válida para el caso, el propio Kelsen

${ }^{32}$ H. KELSEN, Teoría Pura del Derecho, Traducción Roberto J. Vernengo, Universidad Nacional Autónoma de México, México, 1982, p. 29.

33 «El tribunal que tiene que aplicar en un caso concreto las normas generales válidas de un orden jurídico, debe decidir la cuestión de si la norma que aplicará fue producida constitucionalmente, es decir, por vía de un proceso legislativo determinado por la constitución, o por vía de la costumbre en que la constitución delegara». Ibid. p. 257. 
trata de corregir posibles disfunciones, con el derecho a recurrir la sentencia que se haya desviado de la aplicación de la norma, segunda instancia que comportará la correcta ubicación de la norma dentro del sistema, de modo que, la sentencia va a ser justa en función de su argumentación jurídica y de que la norma individual se corresponda con la norma general superior que se presupone justa ${ }^{34}$.

En esta teoría, la garantía de un juez imparcial no existe como tal sino que exige un juez neutro en la previa adopción de la decisión que resolverá, no con un ejercicio de subsunción de la norma, sino aplicando el conjunto normativo dentro de la interpretación que le ofrece la validez de la norma superior, al margen de sus valoraciones políticas y morales, que son para Kelsen enteramente irracionales ${ }^{35}$.

\section{$3^{\circ} \quad$ El juez dentro de un sistema de reglas en Hart}

H. L. A. Hart en su obra «The Concept of Law» pretende configurar un sistema jurídico para una sociedad contemporánea, actual y compleja, y por ello configura una estructura del derecho al margen de la justificación moral de las prácticas jurídicas que se desarrollen, mostrando atención preferente al «lenguaje» que usan legisladores, jueces y ciudadanos al referirse a asuntos jurídicos.

Para Hart, la crisis del positivismo vino en no haber incluido la noción de «regla» sin la cual es imposible explicar la estructura y funcionamiento del derecho, para este autor, la clave del sistema está en las reglas y dentro de ellas, diferencia entre reglas primarias que imponen deberes positivos y negativos -acciones $\mathrm{u}$ omisiones a los individuos- y reglas secundarias que otorgan potestades a los particulares o a las autoridades públicas para crear, modificar, extinguir o determinar los efectos de las reglas de tipo primario y, a su vez, se distingue entre el punto de vista interno y externo de éstas.

En el sistema de reglas, el juez debe cumplir con la labor judicial que le viene atribuida por una regla secundaria para dictar sentencias (reglas primarias), que aún Hart diferencia de las reglas de adjudicación, aquellas que refieren al ejercicio de la función judicial, de las reglas de cambio, las cuales indican el procedimiento para que las

${ }^{34}$ Ibíd. pp. 261-262

${ }^{35} \mathrm{H}$. Kelsen considera que la aplicación e interpretación de la norma no puede verse alterada por factores externos, «Si el conflicto apareciera en una misma sentencia judicial -lo que sólo sería posible si el juez padece de una perturbación mental-, tendríamos un acto carente de sentido y, por ende, como se mostró en lo que; antecede, no contaríamos con ninguna norma jurídica objetivamente válida», ibíd., p. 217. 
reglas primarias cambien y la regla de reconocimiento, regla secundaria última que permite reconocer «el linaje» y determinar la pertenencia de una norma al sistema jurídico ${ }^{36}$.

En este modelo, la imparcialidad judicial se mide en función de si el litigio está o no reglado porque para Hart, el juez debe aplicar prima facie la regla de derecho positivo que dé solución al litigio que se le somete a debate aunque entiende que este operador jurídico necesita técnicas de interpretación por cuanto el derecho se compone de palabras y adolece de una vaguedad congénita encontrándose en ocasiones el juzgador en una zona de penumbra en la que va a ser difícil la subsunción de la norma y, en tales casos, este hermeneuta jurídico se le permite una irremediable discrecionalidad judicial ${ }^{37}$.

Por tanto, los casos reglados no requieren la concurrencia de la garantía de la imparcialidad del juzgador ya que éste, los resolvería conforme a las reglas jurídicas vigentes, aplicando la ley de manera neutral, mediante un método básicamente subsuntivo y donde la legitimidad de la decisión judicial queda sometida a la legalidad de la regla, por el contrario, en los asuntos no reglados, aquellos en los que no se disponga de una regla clara y preestablecida, el juez puede acudir a la discrecionalidad ${ }^{38}$ basada en sus valores morales, en tales supuestos, la exigencia de imparcialidad del juzgador, como garantía procesal, resultaría imprescindible por cuanto para dar contenido y validez a su decisión se le está permitiendo buscar esa respuesta fuera de las reglas, pudiendo ser parcial conforme al prejuicio o preferencia que tuviera con el objeto de enjuiciamiento, de modo que, en estos, el fallo judicial no dependerá de la aplicación neutra del derecho y la sentencia no va a ser justa en función de que se ajuste a un patrón jurídico preestablecido sino al sentido que el magistrado considere más adecuado, el cual necesariamente incluirá criterios propios y subjetivos del juzgador.

${ }^{36}$ La equivalencia en el ordenamiento jurídico español estaría en la Constitución, regla de reconocimiento por la cual « lo que la Constitución dice es Derecho», C. RODRÍGUEZ, La decisión judicial: el debate Hart-Dworkin, Siglo del Hombre Editores, 1999, p.27.

${ }^{37} \mathrm{H}$. L. A. Hart fundamenta la discrecionalidad en un deber moral de los jueces de apelar a «algo fuera del sistema oficial por referencia a lo cual el individuo debe resolver, en última instancia, sus problemas de obediencia». H. L. A. HART, the Concept of Law, Oxford University Press, Oxford, 1993, pp. 205-206.

${ }^{38}$ Algunos autores consideran que la palabra discrecional debe ser entendida como sinónimo de «libre» o «no reglada» como refiere F. LAPORTA sobre las relaciones entre la moral y el Derecho, «Ética y Derecho en el pensamiento contemporáneo», en Victoria Camps (ed.). Historia de la Ética, 3: "La Ética Contemporánea», Crítica, Barcelona, 1989, p. 250. 


\section{4. $\quad$ El juez dentro de una discrecionalidad judicial}

Frente a este sistema, se levanta Dworkin quién critica los argumentos de Hart porque entiende que acudir a la discrecionalidad judicial supone que sólo en los casos no reglados es donde el juez ejercita su buen juicio y no en los casos reglados que se limita a aplicar las reglas preestablecidas, además considera que en los ordenamientos jurídicos, los jueces no se encuentran habilitados para crear normas sino que argumentan sus decisiones conforme la utilización de reglas, principios jurídicamente derivados o de moral política.

\section{5. $\quad$ El juez dentro de un sistema de principios}

La importancia de la función judicial en el sistema norteamericano es enorme basada fundamentalmente en la percepción por la ciudadanía de que los problemas sociales más importantes son decididos y resueltos por los jueces a los que se les ha reconocido el derecho de fundamentar sus decisiones en la propia Constitución, antes incluso que en la propia ley ${ }^{39}$.

Ronald Dworkin se presenta como uno de los principales defensores de una fusión entre las reglas del derecho positivo y los principios éticos objetivos con el objetivo de configurar una realidad normativa que él denomina «derecho como integridad», para este autor los principios forman parte esencial del derecho y como informadores que son de todo el ordenamiento jurídico, son capaces de fundamentar una sola respuesta correcta, incluso para los casos difíciles (hard cases).

Rechazada la tesis de la discrecionalidad judicial, Dworkin configura un modelo descriptivo adecuado y justificativo para dar respuesta a los casos difíciles, por ello diferencia las reglas de los principios, las primeras son normas concretas reguladoras de las posibilidades y condiciones de acción de los particulares, describiendo taxativamente el supuesto de hecho al que se aplican, por el contrario, los principios representan directivas jurídicas, carecen de una descripción al supuesto de hecho al que han de aplicarse y gozan de un fundamento de justicia, Dworkin también admite que, en ocasiones, no resulta claro si una norma es un principio o una regla y, en el caso de existir conflicto (regla/principio), éste se resolvería por un esquema de colisión

${ }^{39}$ Con el célebre caso Marbury v. Madison (año 1803), el Tribunal Supremo de los Estados Unidos reconoce la «judicial review» de la constitucionalidad, cada juez juzga sobre la conformidad con la Constitución, de las leyes, los precedentes y el Derecho en general. 
entre principios, usando la ponderación que ya no sería de regla/principio sino entre éste y el principio que subyace a la regla y, conforme a la jerarquía que existe entre los diferentes principios, está ofrecería una solución al caso en concreto, de tal manera que, la discrecionalidad judicial desaparecería.

En este modelo judicial basado en principios, el juez debe argumentar el dilema jurídico que se le plantea, mediante un razonamiento que consiste «en la utilización de una amplia red de principios jurídicamente derivados o de moral política ${ }^{40}$, su labor judicial se centrara en establecer una decisión ordenada en la aplicación de reglas, principios y antecedentes jurisprudenciales y, encontrándose ante dos posibles alternativas (caso difícil), el magistrado deberá decantarse por la que esté mejor justificada en base a las convicciones morales y políticas que subyacen en toda comunidad, siendo tal elección, una responsabilidad propia del juzgador; de manera que, no hay zonas de penumbras porque aunque no existan reglas jurídicas aplicables al caso concreto, siempre habrá principios que sirvan como base para adoptar la decisión judicial ${ }^{41}$.

Dworkin configura la imparcialidad judicial como principio, frente a las prácticas jurídicas vigentes en los Estados Unidos e Inglaterra y respecto a las tesis del convencionalismo ${ }^{42}$ y pragmatismo ${ }^{43}$, a modo de virtud de «derecho como integridad», garantía por la que los jueces deben tratar a los ciudadanos conforme a los principios de moralidad política plasmados en las instituciones de la comunidad, de tal modo que, la decisión del juez imparcial se encuentra en la aplicación de la regla, que está sustentada por principios, respecto de los que el juzgador no tiene libertad de creación.

En este sistema, la imparcialidad es una garantía procesal previa y necesaria en todo asunto, en donde el juez no va adoptar un fallo

${ }^{40}$ R. DWORKIN, R. ¿Es el derecho un sistema de reglas? (versión castellana de Javier Esquivel y Juan Rebolledo), Instituto de Investigaciones Filosóficas, Universidad Nacional Autónoma de México, p. 41.

${ }^{41}$ La reacción de Hart frente a las críticas de Dworkin será un post scriptum a su obra «El concepto de derecho» (publicado tras su muerte, por Joseph Raz) defendiendo que el mismo Juez Hércules se puede encontrar con casos difíciles que le conduzcan a dos o más interpretaciones siguiendo los principios preestablecidos y, en tales casos, Hércules tendrá inexorablemente que escoger acudiendo a una discrecionalidad judicial.

${ }^{42}$ El Derecho consiste sólo en reglas claramente preestablecidas, normas que deben ser interpretadas por el juez de acuerdo con la intención del legislador y no pueden ser adaptadas a los casos nuevos.

${ }^{43}$ Tesis que considera que los jueces deben atender más a las consecuencias sociales de sus decisiones que a las reglas vigentes y a los precedentes judiciales. 
avalorativo, puesto que la decisión judicial no la puede reducir a la aplicación de la norma, sino que en la formación de la sentencia usará una argumentación cognoscitiva basada en la aplicación de principios, los cuales, exigen acudir a criterios de ponderación y por ende valorativos a fin de hallar la respuesta jurídica al caso planteado y en los que, el juzgador no debe tener más motivos para decidir que lo que justifica la propia función judicial.

Dando un paso más en la evolución de los sistemas judiciales en el siglo XX, estos encuentran influencia en la tesis de Gustav Radbruch, creada para hacer frente a la obediencia a las normas injustas promulgadas por el nacionalsocialismo y que dieron lugar a los aberrantes episodios de la Segunda Guerra Mundial, doctrina que defiende, que el juez debe aplicar el derecho positivo pero no cuando la norma es extremadamente injusta porque se trata de un falso derecho (lex injusta non est lex) ${ }^{44}$. Este planteamiento origina en pleno siglo XX un amplio debate sobre la validez y obediencia al derecho en el caso de la existencia de leyes injustas y, al propio tiempo, la disputa entre derecho y moral, positivismo o iusnaturalismo y la posibilidad de alcanzar una vía de conciliación entre ambos.

\section{6. $^{\text {o }} \quad$ El juez dentro de un derecho dúctil}

Gustavo Zagrebelsky define al Derecho constitucional como un conjunto de materiales de construcción formado por reglas, principios y valores jurídicos donde el resultado no es obra de la Constitución sino de la política constitucional que lo construye según las combinaciones posibles que se realicen de esos materiales ${ }^{45}$.

En una posición intermedia entre un derecho compuesto por reglas y principios, hay que situar a Zagrebelsky, quién excluye un modelo positivista rígido ${ }^{46}$ y apuesta por principios constitucionales plurales y dúctiles, criterios objetivos orientadores y correctores de la ley que deben ser interpretados por el juzgador a fin de salvar las posibles tensiones entre ley/realidad y normas/principios mediante un ejercicio de ponderación al caso concreto. El autor diferencia reglas y principios, las primeras son leyes reforzadas a pesar de que estén escritas en la

${ }^{44}$ G. Radbruch en «Relativismo y derecho», Temis, SA, Bogotá, 1999, p. 35.

${ }^{45}$ G. Zagrebelsky, El derecho dúctil. Ley, derechos, justicia (Traducción de Marina

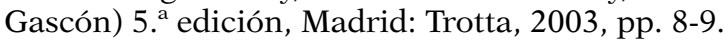

${ }^{46}$ Zagrebelsky lo rechaza «Si el derecho sólo estuviese compuesto de reglas no sería insensato pensar en la «maquinización» de su aplicación», G. ZAGREBELSKY, El derecho dúctil..., op.cit., p.110. 
Constitución y se agotan en su aplicación, no tienen fuerza constitutiva, por el contrario, los principios desarrollan un papel constitutivo del orden jurídico, de este modo Zagrebelsky llama a «comprender el mundo de valores, las grandes opciones de cultura jurídica de las que forman parte y a las que las palabras no hacen sino una simple alusión ${ }^{47}$; en este modelo, también conviven principios y valores, los cuales hacen imposible la existencia de formalismo entre los principios y, resulta posible que los valores se positivizen en normas de principio, resultando todos ellos necesarios para mantener la unidad e integridad de una Constitución dentro de una sociedad pluralista ${ }^{48}$.

De esta forma, los Estados constitucionales modernos se conectan con el derecho natural a través de los principios constitucionales presentes en la Constitución ${ }^{49}$, como medio de incorporar principios morales del derecho natural al ordenamiento jurídico, aunque el propio Zagrebelsky puntualiza el acercamiento al iusnaturalismo y distingue su origen en que «en los ordenamientos jurídicos basados en los principios, en cambio, aquel paso no depende de un valor reconocido a priori, como sucede para la doctrina del derecho natural, sino de normas de derecho de positivo ${ }^{50}$.

En la apuesta por la ductilidad del derecho, el juez necesita de un pluralismo metodológico en la interpretación del derecho por cuanto el ordenamiento no le va a ofrecer siempre una única solución y por ello, la norma debe conectarse con el caso y sus exigencias, esto es, es el método el que tiene que estar en función de la búsqueda y donde la voluntad del legislador también deberá de ser interpretada ${ }^{51}$.

${ }^{47}$ Ibid., p. 110.

${ }^{48}$ Ibid., pp.14-15.

${ }^{49}$ J. L Muñoz de Baena «Los principios juegan, además, un papel llamado a atenuar, si no a borrar, la vieja contraposición entre iusnaturalismo y positivismo: por una parte, constituyen una suerte de nuevo derecho natural, inspirador de los desarrollos legislativos; por otra, son a la vez la manifestación más elevada del derecho positivo», «Fundamentos filosóficos de los Derechos Humanos», Presente, pasado y futuro de los Derechos Humanos, Comisión Nacional de los Derechos Humanos, UNED, México, 2004. p.122.

${ }^{50}$ G. ZAGREBELSKY, El derecho dúctil...,op.cit., p. 115.

${ }^{51}$ Refiriéndose a la concepción interpretativa del modelo constitucional, M. ALFONSO RUIZ señala «la decisión judicial no puede ya ser vista como el fruto de la subsunción de los hechos en una premisa mayor normativa simplemente extraída del Derecho, sino que tal premisa ha de construirse de forma compleja -la alusión a la hermenéutica es aquí obligada- en un equilibrio entre las exigencias del caso, que proceden de una realidad interpretada a la luz de los valores constitucionales, y la regulación normativa abstracta», "Del dúctil derecho y la virtuosa necesidad en Anuario de Filosofía del Derecho XIII (1996), p. 163. 
Siguiendo la línea marcada por Zagrebelsky, de conformidad con la ductilidad del derecho en la función de impartir justicia, todo juez será discrecional en la elección del método de interpretación del caso ${ }^{52}$ porque lo resolverá no sólo aplicando reglas sino pudiendo reinventar el sentido de la norma mediante el uso de principios constitucionales. los cuales contienen las líneas maestras de comprensión e interpretación de la actividad jurisdiccional y de la justicia constitucional ${ }^{53}$; en este modelo judicial, la decisión del juez ya no se agotará con su correspondencia a la ley sino en su ponderación con los principios constitucionales encargados de enjuiciar la validez de la norma, en tal sentido, el juzgador será autor y responsable de la decisión que toma porque no sólo estará llamado a interpretar la ley sino a realizar un juicio previo a ella a fin de dotar de sentido racional-constitucional la sentencia.

Con este objetivo, la labor judicial para resolver el asunto ha pasado de la teoría de subsunción a la norma, a un método argumentativo en el que se incluyen normas y principios constitucionales, desde luego que, en esta tarea, el juez debe previamente ser independiente e imparcial porque tales garantías procesales son las que permiten neutralizar la subjetividad del juzgador y la incertidumbre de su influencia para la resolución del caso concreto, a la par de la confianza que ofrecen al justiciable en el correcto funcionamiento de la administración de justicia.

En definitiva, los sistemas judiciales de los Estados constitucionales de Derecho dejan un cierto margen de discrecionalidad al juzgador para formar la decisión judicial conforme lo que éste pueda considerar justo, si bien esta concesión siempre estará limitada y controlada por el contenido y alcance de los principios constitucionales, en los que residirán los valores presentes en el ordenamiento que les doten de sentido y que a su vez impliquen el cierre a cualquier clase de arbitrio judicial, de tal manera que, la presencia de unos principios constitucionales permiten ponderar el razonamiento jurídico y, la ausencia de normas y principios, faculta a los jueces a la búsqueda del ejercicio de racionalidad en otros a fin de poder resolver los casos difíciles, incluso llegando a la solución que él mismo pueda

${ }^{52}$ «El caso, para el juez y para la ciencia jurídica, es esencialmente un acontecimiento problemático que plantea la cuestión de cómo responder al mismo, de cómo resolverlo en términos jurídicos. Para el derecho, por tanto, el caso no es algo que deba ser simplemente registrado. Sino algo que debe ser resuelto», G. Zagrebelsky, El derecho dúctil. Ley, derechos, justicia (Traducción de Marina Gascón) 5. edición, Madrid, Trotta, 2003, p.136.

${ }^{53}$ Sobre el futuro de la justicia constitucional, G. Zagrabelsky, «Jueces constitucionales». Discurso oficial pronunciado frente al Presidente de la República el 22 de abril de 2006 en Roma con motivo de la celebración del 50. a aniversario de la Corte Constitucional italiana. 
darse $\mathrm{e}^{54}$ en aquellos casos en los que el derecho no le ofrezca una sola respuesta correcta o existan diversas posibilidades jurisprudenciales. En tales supuestos, la crítica ante la posible falta de imparcialidad del juzgador cuando éste haya optado por aquella decisión que mejor respuesta le muestren los principios constitucionales es consecuencia, como indica el propio Zagrebelsky, «del carácter pluralista de la sociedad actual y de esa sociedad parcial que es la comunidad de los juristas y operadores jurídicos ${ }^{55}$ y ello porque el pluralismo social revela la conexión entre la norma, que el propio juez responsable interpreta, con los valores en los que descansa el ordenamiento constitucional, que son los que también permiten a todo juez imparcial un margen de libertad ineludible; en esta ductilidad del derecho, los principios constitucionales son herramientas para moldurar el sentido de las normas y el operador jurídico debe elegir la solución hermenéutica que mejor se adapte a aquellos, encontrándose con esta habilitación que le otorga el propio Estado constitucional de Derecho al estar en continua adaptación por la presencia de unos materiales de construcción que van permanentemente moldeándose al ser acomodados al contexto cultural existente en cada momento sobre la base de una serie de valores preestablecidos, si bien Zagrebelsky precisa «el sentido y el valor que resultan relevantes desde el punto de vista de la aplicación judicial tienen un significado objetivo y no subjetivo» ${ }^{56}$.

En realidad, esto no es criterio que interfiera en la imparcialidad judicial sino en la delimitación de lo que es justo y de lo que no lo es, se ha visto, como el ordenamiento jurídico no es pleno, las formulaciones normativas en ocasiones adolecen de vaguedad o de contingencia respecto a la vida jurídico real y que, si bien debe existir un principio de justicia, este se diferencia del concepto que cada uno tiene de la justicia, no sólo porque cada uno tiene el suyo propio, sino porque la concebimos como un ideal, y los ideales están en cada pensamiento humano y no en el ordenamiento jurídico.

\section{CONCLUSIONES}

1. ${ }^{\circ}$ En un Estado Social y democrático de Derecho la percepción de que la administración de justicia actúa con imparcialidad constituye un

${ }^{54}$ En este sentido, L. PRIETO SANCHÍS «El constitucionalismo de principios, ¿entre el positivismo y el iusnaturalismo? (A propósito de «El Derecho dúctil» de Gustavo Zagrebelsky). Anuario de Filosofía del Derecho XIII (1996), p 140-141.

${ }^{55}$ G. ZAGREBELSKY, El derecho dúctil..., op.cit.,p. 137.

${ }^{56}$ Ibid., p. 137. 
elemento esencial para lograr la confianza de los ciudadanos en las decisiones judiciales que a diario se adoptan por los Juzgados y Tribunales.

2. ${ }^{\circ}$ El derecho a un juez imparcial está reconocido por la Constitución Española y se traduce en un principio constitucional y en una garantía procesal donde el destinatario es el justiciable, la imparcialidad no puede ser una garantía descriptiva del proceso sino prescriptiva, debe ser un deber para el juez a riesgo de que el procedimiento quebrante tal derecho.

3. ${ }^{\circ}$ El derecho fundamental a tener un juez imparcial como garantía procesal conlleva a que el juzgador no guarde conexión con el justiciable, ni deba tener prejuicio o contacto previo con el objeto de litigio, por eso de que las apariencias son importantes, resultando que la posible vinculación del juez con un asunto en concreto, bien con los litigantes o/y bien con el objeto de proceso, puede poner en entredicho el debido cumplimiento de la función judicial.

4. ${ }^{\circ}$ Y para evitar y neutralizar cualquier sospecha, la exigencia de la imparcialidad judicial debe ser máxima y debe proyectarse tanto en la actividad procesal, como en la actividad extraprocesal del juez, persona que con carácter previo le toca conocer de un determinado procedimiento, por ello deben definirse las reglas que eviten cualquier legítima duda que pudiera existir en relación a la falta de idoneidad de este magistrado para el conocimiento del asunto.

5. ${ }^{\circ}$ En el mundo jurídico europeo se viene produciendo un desplazamiento de la concepción del derecho de un sistema de normas hacia un sistema basado en principios donde el poder se somete a la Constitución.

6. ${ }^{\circ}$ En los Estados constitucionales de Derecho, el juzgador ya no resuelve de acuerdo con lo que dice expresamente la ley (formalismo legalista o positivismo jurídico) sino que es la ley la que debe ser interpretada conforme a un proceso de verificación y contraste con los principios y valores imperantes en la colectividad que la propia Constitución permite.

7. ${ }^{\circ}$ Si la imparcialidad judicial constituye una de las garantías esenciales que debe reunir todo proceso justo, se debe aceptar que todo asunto requiere de una actividad humana racional que utiliza métodos de interpretación para mostrar las razones que justifiquen la decisión judicial donde la sentencia no se puede crear de manera automática sino que un juez responsable debe encontrar la solución adecuada y, ante dos o más opciones posibles, optará por aquella más razonable y justa mediante el razonamiento jurídico que le permita el ordenamien- 
to jurídico vigente en cada momento y donde la decisión judicial ya no se agota con su correspondencia a la ley sino con su conformidad con los principios constitucionales establecidos.

\section{BIBLIOGRAFÍA}

AGUILÓ REGLA, J.,, «Independencia e imparcialidad de los jueces» en Biblioteca Jurídica virtual del Instituto de Investigaciones jurídicas de la UNAM, pp. 94-109.

ALFONSO RUIZ, M., "Del dúctil derecho y la virtuosa necesidad en Anuario de Filosofía del Derecho XIII (1996), pp. 159-173.

ANDRÉS IBÁÑEZ, P., «No conviene «matar» al «notario». A propósito de jurisdicción y de Derecho dúctil (en España)» en Anuario de Filosofía del Derecho XIII (1996), pp. 45-56.

— «Imparcialidad judicial e independencia judicial» en Ética judicial, Reflexiones desde jueces para la democracia. Fundación Antonio Carretero, pp. 13-42.

CASTRO CID, B. y MARTÍNEZ MORÁN, N., 18 Lecciones de Filosofía del Derecho, Manual para alumnos de la UNED, Madrid, 2008.

DWORKIN, R., «¿Es el derecho un sistema de reglas?». Cuadernos de crítica. 34 Folleto. Universidad Autónoma de México. 1977.

- La justicia con toga, traducción por Marisa Iglesias e Iñigo Ortiz de Urbina, Marcial Pons, Madrid, 2007.

FERRAJOLI, L., Derechos y garantías. La ley del más débil, traducción por Perfecto Andrés Ibáñez y Andrea Greppi, Trotta, Madrid, 2001.

- Derecho y razón, Trotta, Madrid, 1998.

— «Las Fuentes de legitimación de la jurisdicción» de la jurisdicción en Biblioteca Jurídica virtual del Instituto de Investigaciones jurídicas de la UNAM, pp. 3-18.

FERNÁNDEZ-VIAGAS BARTOLOMÉ, P., El juez imparcial, Comares, Granada, 1997.

GOLDSCHMIDT, W., «La Imparcialidad como Principio Básico del Proceso», Conducta y Norma, Librería Jurídica Valerio Abeledo, Buenos Aires, 1955.

GÓMEZ MARTÍNEZ, C., «El juez ante el caos judicial, Hermes o el Dios de las pequeñas cosas» en Ética judicial: Reflexiones desde 
jueces para la democracia. Fundación Antonio Carretero, Madrid, pp. 101-118.

HART, H. L. A., the Concept of Law, Oxford University Press, Oxford, 1993.

KELSEN, H., Teoría Pura del Derecho, traducción Roberto J. Vernengo, Universidad Nacional Autónoma de México, México, 1982.

- ¿Qué es justicia?, Estudio preliminar por A. Calsamiglia (1982), Planeta De Agostini, Barcelona, 1993.

LAPORTA, F., «Ética y Derecho en el pensamiento contemporáneo», en Victoria Camps (ed.). Historia de la Ética, 3: «La Ética Contemporánea», Crítica, Barcelona, 1989, pp. 250-275.

MUÑOZ DE BAENA, J. L., «Fundamentos filosóficos de los Derechos Humanos» en Presente, pasado y futuro de los Derechos Humanos, Comisión Nacional de los Derechos Humanos, UNED, México, 2004, pp. 93-125.

ORREGO SÁNCHEZ, C., «Un juicio justo: la especificación del juicio legal en la filosofía jurídica analítica, la hermenéutica iusfilosófica y la teoría de la ley natural» Anuario Filosófico 44/3, 2011, pp. 543-564.

OST, F., «Júpiter, Hércules y Hermes. Tres modelos de jueces», en Revista sobre enseñanza del Derecho año 4, número 8, 2007, pp. 101-130.

PRIETO SANCHÍS, L., «El constitucionalismo de principios, ¿entre el positivismo y el iusnaturalismo? (A propósito de «El Derecho dúctil» de Gustavo Zagrebelsky). Anuario de Filosofía del Derecho XIII (1996), pp. 125-158.

RADBRUCH, G., Relativismo y derecho, Temis, SA, Bogotá, 1999.

RODRÍGUEZ, C., La decisión judicial: el debate Hart/ Dworkin, Siglo del Hombre Editores, 1999.

VV. AA., Filosofía del derecho: lecciones de hermenéutica jurídica, Madrid, Universidad Nacional de Educación a Distancia, Madrid, 2006.

ZAGREBELSKY, G., «Jueces constitucionales». Discurso oficial pronunciado frente al Presidente de la República el 22 de abril de 2006 en Roma, Italia con motivo de la celebración del 50. ${ }^{a}$ aniversario de la Corte Constitucional italiana. (Traducción de Miguel Carbonell).

- El derecho dúctil. Ley, derechos, justicia (Traducción de Marina Gascón) 5. a edición, Madrid: Trotta, 2003. 
